\title{
System-Level Reform in Healthcare Delivery for Patients and Populations Living with Chronic Disease
}

\section{Réforme systémique en matière de prestation de soins de santé pour les patients et les groupes atteints de maladies chroniques}

\author{
$\bullet 9$ \\ COMMENTARY \\ COMMENTAIRE \\ Richard Wedge, MD \\ CEO, Health PEI \\ Chair, Atlantic Healthcare Collaboration Executive Committee \\ Charlottetown, PEI
}

\section{Chef de la direction, Health PEI}

Président, Comité exécutif de la Collaboration des organismes de santé de l'Atlantique Charlottetown, I.-P.-É.

Hon. Douglas W. Currie

Former Minister of Health and Wellness

Government of PEI

Charlottetown, PEI

L'ancien Ministre de la Santé et du Mieux-être

Gouvernement de 1'̂̂.-P.-É.

Charlottetown, I.-P.-É.

$$
\propto
$$




\begin{abstract}
Healthcare in Canada has generally not kept pace with the evolving needs of patients since the creation of medicare in the 1960s. Budgets for hospitals, physicians and prescription drugs make up the bulk of spending in health, despite the need for better prevention and management of chronic disease, the needed expansion of home-based care services and the call for reform of front-line primary care. Over the past decade, a number of Canadian health authorities have adopted the US-based Institute for Healthcare Improvement Triple Aim philosophy (better population health, better patient experience and better per capita cost of care) in order to build system-level change. The Atlantic Healthcare Collaboration was one attempt to initiate systemlevel reform in healthcare delivery for patients living with chronic disease.
\end{abstract}

\title{
RÉSUMÉ
}

Dans l'ensemble, depuis la création du régime d'assurance-maladie au cours des années 1960, au Canada, les soins de santé n'ont pas suivi le rythme de l'évolution des besoins des patients. Les budgets des hôpitaux, les médecins et les médicaments sur ordonnance représentent l'essentiel des dépenses en santé, en dépit du besoin de s'attaquer à la prévention et à la gestion des maladies chroniques, du besoin urgent d'élargir les services à domicile et des appels à la réforme des soins primaires de première ligne. Au cours de la dernière décennie, un certain nombre d'autorités sanitaires de partout au Canada ont adopté la philosophie du Triple objectif de l'Institute for Healthcare Improvement (une population en meilleure santé, une meilleure expérience pour le patient et de meilleurs coûts par habitant pour la prestation des soins de santé) dans le but de mener à bien des changements systémiques. La Collaboration des organismes de santé de l'Atlantique visait précisément à engager une réforme systémique de la prestation des soins de santé pour les patients atteints de maladies chroniques.

\section{Introduction}

The lead paper signals a need to move from usual care that is focused on providing episodic and fragmented care to one that offers more holistic and continuous chronic illness prevention and care (Verma et al. 2016). Indeed, what is needed is a better fit between the care that is offered and the care that the population needs - more emphasis on primary healthcare, more effective prevention and management of chronic disease and more resources placed in mental health. There also needs to be greater involvement of patients, families and communities in care co-design as well as disease prevention and management. Getting there will take a broad and coherent set of strategies to significantly transform healthcare in Canada (Denis et al. 2010).

It is a daunting task but a necessary one. From a spending perspective, although growth continues on a modest trend since 2011, total healthcare spending in 2014 in Canada was projected to be $\$ 214.9$ billion $(\$ 6,045$ per person), with $30 \%$ of those dollars allocated to hospital costs alone (CIHI 2014). Per capita healthcare spending in the Atlantic region outpaces that of provinces such as British Columbia, Quebec and Ontario (CIHI 2014). From a population health perspective, Atlantic Canada also has higher risk factors and rates of chronic disease than ever before, indeed, greater than the Canadian average (Statistics 
Canada 2013). In terms of experience of care, the Health Care in Canada survey carried out by Pollara (2014) suggests that Canadians see room for improvement. For example, more than $80 \%$ (including $37 \%$ who strongly support and $46 \%$ who somewhat support) call for more wellness promotion and disease prevention education and support, while more than $80 \%$ (30\% strongly support; $51 \%$ somewhat support) want increased patient involvement in decision-making about the healthcare system (Pollara 2014).

Taken together, reducing the per capita cost of care, improving population health and patient experience of care constitute what the US-based Institute for Healthcare Improvement (IHI) refers to as the Triple Aim (Berwick et al. 2008). Improving care for patients living with chronic disease is the new reality that only a Triple Aim approach can achieve. The Atlantic Healthcare Collaboration for Innovation and Improvement in Chronic Disease (AHC), while finished, continues to be governed by Atlantic health region leadership in partnership with the Canadian Foundation for Healthcare Improvement (CFHI). The AHC was an attempt at pan-Atlantic collaboration intended to move the marker on two of the aims: sustainability and care experience. To be effective, the efforts that the AHC supported must continue but with more emphasis on improving the population health objective of the Triple Aim. Still, it remains a positive example in the Canadian context that collaboration can and does happen - because when a vision is shared, so too can be the agenda required to achieve it.

\section{One-Island Health System Is Making Good on Triple Aim}

In 2010, the government of Prince Edward Island (PEI) created a single, province-wide health authority, Health PEI, to manage the delivery of health services to Islanders. This provincial crown corporation is fully integrated across the health spectrum. In addition to hospitals and hospital services such as diagnostic imaging and laboratory services, Health PEI includes physician payment budgets, long-term care, home care, public health and ambulance services. As the health authority in a small province, Health PEI collaborates with Nova Scotia and New Brunswick to provide complex subspecialty services such as cardiac surgery, neurosurgery, transplant surgery, vascular surgery and thoracic surgery. In other provinces, the ability of health authorities to achieve full integration can be hampered by separate and siloed budgets and management. From the early days of Health PEI, it was recognized that improvements to healthcare services would flow from independent governance and management of a fully integrated provincial health system, while respecting governments' direction on healthcare policy and their ability to fund healthcare for Islanders.

Healthcare consumes almost $45 \%$ of the Atlantic provinces' budget expenditures (CIHI 2014). When Medicare programs were being developed in the 1960s and 1970s, healthcare largely referred to hospital care and physician services. In 2015, the definition of healthcare must be broader - populations are older, many citizens have one or more chronic diseases and hospital/physician care makes up only about half of provincial health expenditures. The provincial governments' coverage for community-based allied health professionals such as physiotherapists, optometrists, social workers, nurse practitioners, nurse educators and psychologists, as well as public coverage for home care, pharmaceuticals and ambulance services, varies widely between provinces. The Canada Health Act does not require provinces to cover non-physician and non-hospital costs. The expansion of publically financed health services is dependent on 
individual provincial government policy direction and provincial fiscal realities.

Growth in health budgets on PEI, as in other provinces, averaged approximately 6-7\% per year over the past decade (CIHI 2014). This was the result of increasing numbers of clinical providers, expansion of healthcare services and pharmaceutical formularies, new technology and improvements to incomes of healthcare workers. These increases were in response to the growing prevalence of chronic disease as well as the growing impatience from Islanders about prolonged wait times. These large, yearly health budget increases did not solve access problems, stimulate system reforms or do much to expand the range of public services. Clearly, increases of this magnitude were unsustainable, so Health PEI, similar to most other health authorities, began to focus on achieving real improvements in the patient care experience at a lower cost.

Triple Aim is a strategic approach that brings about simultaneous and at-scale improvements to individual patient care experience as well as whole-of-population health benefits yielding lower healthcare costs (Berwick et al. 2008). For Health PEI's oneisland health system, the approach is fitting, given that it takes into account the health and health system of all Islanders. In the same way, when the AHC presented an opportunity for Health PEI to collaborate with its Atlantic counterparts - across regions and provinces toward a shared goal of improving patient- and family-centred chronic care - it made sense.

\section{Building Organizational Capacity - The AHC Experience}

Most attempts at reforming the healthcare system have focused on improving wait times, preventing medical errors and reducing costs. The goal of the AHC was to promote and support interdisciplinary team care for chronic disease in the community setting. This team- based care is expected to decrease demand on primary care physicians' time, reduce emergency room visits, reduce hospital admissions for ambulatory care sensitive conditions, return patients to their own homes sooner if admitted to a hospital and improve patients' overall healthcare experience.

Health authority CEOs and senior managers from across Atlantic Canada's (then) 17 health authorities as well as senior officials from the provincial departments of health came together with CFHI in January 2012 in St. John's, Newfoundland, to set a vision for the AHC. Together, the AHC built a network of organizational, regional and provincial teams to share evidence-informed, systemlevel solutions, first with their own organization, but eventually with the other teams. The AHC executive committee provided both local leadership and Atlantic Canadian leadership. The AHC executive committee members also committed resources for the planning, implementation and evaluation of the individual projects.

The goal of the AHC was to ensure that clinical professionals at all levels of the health system had access to the knowledge and tools they needed to improve chronic disease management and prevention. In addition, the clinicians would build and improve upon provincial and inter-provincial supports for collaboration, networking and engaging their peers in managing the rising prevalence of chronic disease. The clinicians and administrators gained knowledge, skills and confidence to initiate, sustain, spread and lead future change initiatives within their own organizations. Health authority staff members were required to apply the knowledge and skills they learned by leading initiatives in their own organizations. The initiatives identified were healthcare services with rising demand, prolonged wait times or other concerns identified by the local health authority. 
To support the teams, CFHI provided them with access to expert faculty, academic mentorship and improvement coaching and regular, in-person workshops and webinars that combined educational supports in quality improvement alongside chronic care improvements. All of this was in an effort to create a system of support around the teams as they designed, implemented and evaluated their chronic disease management and prevention improvement initiatives.

As the lead authors indicate, improvement takes time, often outlasting the timeline of a collaborative (Verma et al. 2016). Many of these teams are now enrolled in other CFHI collaboratives or quality improvement programs in order to continue their improvement journeys. That is the case for the two Health PEI teams, for example, with one now enrolled in an international Triple Aim program offered by IHI in partnership with CFHI - the Better Health and Lower Costs Collaborative for Patients with Complex Needs collaborative - with the other enrolled in a pan-Canadian CFHI spread collaborative - the INSPIRED Approaches to COPD collaborative.

Improvement is not a point in time; teams require ongoing access to such supports offering professional development, access to best evidence and practice experts as well as networks of peers making gains against the same improvement objectives. The lead paper reports that the AHC was successful at creating these kinds of linkages - connecting providers and teams with one another in a common improvement pursuit that became stronger over the course of the collaboration (Verma et al. 2016). Because of these supports, some of these teams are already making important gains, for example, the key results shown in Figure 1 below:

Figure 1. Key Milestones of the Four AHC Teams That Were Successful in Implementing and Evaluating Their Improvement Projects During the Collaborative

\section{Central Health (NL)}

Redesigned an asthma outpatient clinic into a Respiratory Ambulatory Care Centre

New standing orders and improved care pathways provide standardized and evidence-informed care

New COPD outreach program uses telehealth and home-based support to provide:
$\Gamma$

self-management education
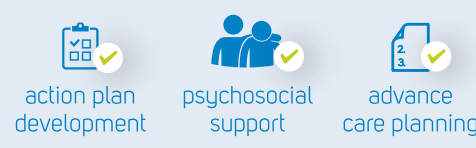

60

Patients

in just

2 months

\section{Health PEI}

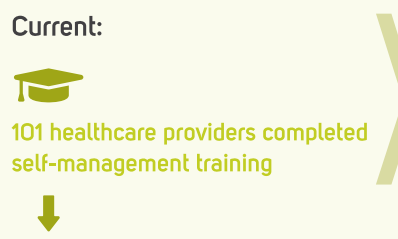

In 3 years:

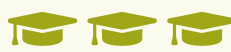

$1,000+$ healthcare providers will be trained

Providers report greater confidence in their self-management ability and likelihood to implement self-management

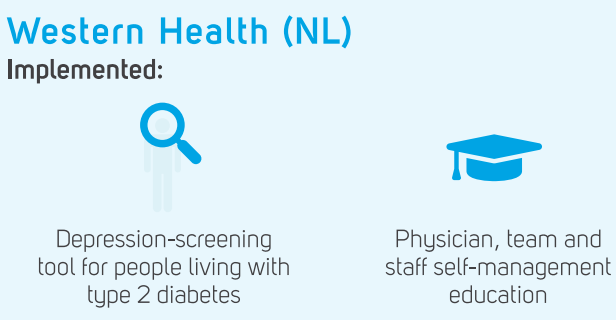

Patients report:

『) Convenient appointments

『) Helpful diabetes management plans and education sessions

『. Confidence in diabetes self-management

\section{Horizon Health Network (NB)}

Youth report improvement in concerns about:
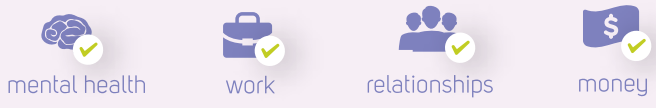

Decrease in:

\Emergency room visits

\ Hospital admissions for a mental health diagnosis

- Use of community mental health services 
At least one factor that assisted in making these gains (in what is a relatively short period) is that the AHC brought on board initiatives that were decidedly local priorities and for which some capacity was already invested locally. From a cost containment and benefits-realization perspective, this was a pragmatic approach in that it surrounded existing improvement teams with the support they needed to initiate and manage change. It also kept those initiatives and teams on the senior leadership's agendas, as the AHC executive committee met regularly (and continues to do so) to share improvement progress and milestones. Similarly, the AHC executive committee shares these progress markers with our ministerial colleagues - another benefit of a collaborative model, as it enables sharing information across regions and provinces.

The time it takes to realize these modest, but important improvements cannot be overstated. And it will take longer to realize the population health aim of the Triple Aim. On this objective, we simply need to pay more concerted attention to primary care and public health initiatives to alleviate risk factors for chronic disease like smoking, obesity and inactivity; as well, we must continue to provide self-management education and supports to those living with chronic disease. To do so means inviting people - patients, family caregivers and communities - to the improvement table alongside front-line providers, managers and policy makers. Arguably, the AHC did make efforts to bring patients to the table, but it needs to be more definitively part of the equation - involving patients as partners is not a "nice to have" but a "must have." In fact, involving patients in the design of their health services leads to a more effective and meaningful healthcare system. In the same way, any at-scale improvements require greater involvement of the policy arm, for example, to help gauge whole-of-province and whole-of-population gains in cost containment and health.

\section{Creating Supportive Policies and Legislation - A Direction Forward}

Although there have been many successful improvements to healthcare throughout Canada in recent years, Canadian healthcare continues to be a laggard in comparison to other developed countries. Canada's current Commonwealth Fund ranking is 10th out of 11 countries (with the US being 11th) overall (The Commonwealth Fund 2014). Canada's rank is near the bottom on safety, access, quality and efficiency. Many governments and healthcare managers feel that further increases to spending without structural change, policy change and physician payment reforms will not lead to improvements in our health system.

Government policy supporting collaborative interdisciplinary team-based primary care, reduction in solo physician practices, reduction of volume-based fee-for-service physician care, shared professional accountability for performance and outcomes, as well as a robust clinical information system are needed to move the health system forward. These changes need to be aligned with physician payment agreements as well as negotiations with all front-line clinical staff.

Governments generally signal their priorities via changes to current healthcare policy or the introduction of legislative changes to the organization of health delivery. Legislation is accustomed to realigning health system components to ensure that change occurs. This approach has resulted in a number of provincial and regional health authorities, in various forms, in various provinces. In the past, the introduction of legislation has also served to promote accountability to health providers, hospitals or health system management. Strategic plans, annual business plans and annual reports to the public ensure that 
specific performance targets are set and achieved and that health authorities are held accountable. Health authorities have also realized innovative and efficiency changes to the delivery of healthcare via clinical and health system administrator collaboration.

\section{Conclusion}

The AHC organizational teams worked together to develop, implement and embed sustainable improvement initiatives in chronic disease prevention and management. Through sharing their improvement work, these teams are helping to promote the sustainability of healthcare services in Atlantic Canada. The AHC also took a Triple Aim lens in its focus on improved care experience for people living with chronic disease throughout the Atlantic provinces while simultaneously addressing health system sustainability. It's an example of how working together, across regions and provinces, makes it possible to enhance team-based and organizational capacity to improve care.

Leadership plays a critical role in supporting innovative care delivery models and the spread of these ideas and mechanisms to others. These front-line staff, who initiated and developed approaches to care, must be supported and evaluated, and the knowledge they gained must be spread to other organizations. Atlantic Canadian health authorities need to continue to work together to develop clinician leadership as well as develop partnerships with clinical organizations that focus on patient-centred care and promotion of best practices and innovations.

All of us have had first-hand experience with healthcare in Canada - the good and the bad. To achieve the vision of a high-performing healthcare system, all governments, health authorities, clinicians and the public need to work together and commit to a common goal of highest quality health services.

\section{References}

Berwick, D.M., T.W. Nolan and J. Whittington. 2008. "The Triple Aim: Care, Health, and Cost." Health Affairs, Millwood 27(3): 759-69. doi:10.1377/ hlthaff.27.3.759

Canadian Institute of Health Information (CIHI). 2014. National Health Expenditure Trends, 1975 to 2014. Retrieved March 19, 2015. <http://www.cihi.ca/ web/resource/en/nhex_2014_report_en.pdf >.

Denis, J-L., H.T.O. Davies, E. Ferlie and L. Fitzgerald. 2010. "Assessing Initiatives to Transform Health Systems: Lessons for the Canadian Healthcare System." Retrieved March 19, 2015. <http://www. cfhi-fcass.ca/Libraries/Commissioned_Research_ Reports/JLD_REPORT.sflb.ashx>.

Pollara. 2014. Health Care in Canada Survey. Retrieved March 19, 2015. <http://www.hcic-sssc.com/>.

Statistics Canada. 2013. Statistics Canada Catalogue no. 82-228-XWE. Ottawa. Released December 12, 2013. Retrieved March 19, 2015. <http://www12.statcan.gc.ca/health-sante/82-228/index.cfm?Lang=E >.

The Commonwealth Fund. 2014. Mirror, Mirror on the Wall, 2014 Update: How the U.S. Health Care System Compares Internationally. Retrieved March 19, 2015. $<$ http://www.commonwealthfund.org/publications/ fund-reports/2014/jun/mirror-mirror $>$.

Verma, J.Y., J.-L. Denis, S. Samis, F. Champagne and M. O'Neil. 2016. "A Collaborative Approach to a Chronic Care Problem." Healthcare Papers 15(Special Issue, January): 19-60. doi:10.12927/ hcpap.2016.24503 